\title{
Impact of COVID-19 on management of urogynaecology patients: a rapid review of the literature
}

\author{
Jemina Loganathan (10) - Stergios K. Doumouchtsis ${ }^{1,2,3,4}$. CHORUS: An International Collaboration for Harmonising \\ Outcomes, Research and Standards in Urogynaecology and Women's Health
}

Received: 7 October 2020 / Accepted: 2 December 2020 / Published online: 3 February 2021

(C) The Author(s) 2021

\begin{abstract}
Introduction and hypothesis The coronavirus (COVID-19) pandemic has impacted health systems worldwide. There is a continuing need for clinicians to adapt practice to facilitate timely provision of medical care, whilst minimising horizontal transmission. Guidance and recommendations are increasingly available, and this rapid review aimed to provide a timely evidence synthesis on the current recommendations surrounding urogynaecological care.

Methods We performed a literature review using PubMed/Medline, Embase and Cochrane and a manual search of national and international societies for management recommendations for urogynaecological patients during the COVID-19 pandemic.

Results Nine guidance documents and 17 articles, including 10 reviews, were included. Virtual clinics are recommended for new and follow-up patients, to assess and initiate treatment, as well as triage patients who require face-to-face appointments. Outpatient investigations such as urodynamics and cystoscopy for benign indications can be deferred. Prolapse and continence surgery should be suspended, except in specific circumstances such as procidentia with upper tract complications and failed pessaries. There is no evidence to support a particular route of surgery, but recommendations are made to minimise COVID-19 transmission.

Conclusions Urogynaecological patients face particular challenges owing to inherent vulnerabilities of these populations. Behavioural and medical therapies should be recommended as first line options and initiated via virtual or remote clinics, which are integral to management during the COVID-19 pandemic. Expanding the availability and accessibility of technology will be increasingly required. The majority of outpatient and inpatient procedures can be deferred, but the longer-term effects of such practices are unclear.
\end{abstract}

Keywords Coronavirus · COVID-19 $\cdot$ Surgical prioritisation $\cdot$ Telemedicine $\cdot$ Urogynaecology

\section{Introduction}

Coronavirus (COVID-19) disease caused by the SARS-CoV-2 virus was first declared as a pandemic by the World Health Organization (WHO) on 11 March 2020 [1]. Since then it has

Stergios K. Doumouchtsis

sdoumouc@sgul.ac.uk

1 Epsom and St Helier University Hospitals NHS Trust, Dorking Road, Epsom KT18 7EG, UK

2 St George's University of London, London, UK

3 Laboratory of Experimental Surgery and Surgical Research N.S. Christeas, Athens University Medical School, Athens, Greece

4 American University of the Caribbean, School of Medicine, Pembroke Pines, FL, USA continued to rapidly spread worldwide impacting all aspects of life, not least medical care and how clinicians assess and treat patients. Medical providers worldwide have been required to adapt and streamline services to minimise unwarranted, multiple healthcare facility attendances and patient contact where possible, by conducting remote consultations, delaying nonurgent visits and optimising provision of one-stop services.

The urogynaecology scope of practice involves, to a significant proportion, care and management of elderly and vulnerable patients and therefore these measures are of particular importance. As the pandemic continues, national and international societies and organisations have published guidance for management mainly based on consensus and expert advice given that evidence base to support recommendations is still scarce [2-5].

Rapid reviews are a method of knowledge or evidence synthesis [6] to produce information in a more timely manner than traditional systematic reviews [7]; therefore, they are 
particularly useful for new and emerging topics. Rapid reviews involve an expedited process with omission of certain steps usually performed in a systematic review.

Given the rapid evolution of evidence, recommendations, policies and clinical management adaptations, a rapid review on the current evidence and recommendations is highly warranted. Since the COVID-19 pandemic was declared, several publications have appeared providing narrative reviews in order to bring all the relevant information from the guidelines together in one document, to support patient care [8-10]. These studies summarise and review published guidelines, original studies, consensus statements, opinions and comments in peerreviewed journals, and professional organisations and societies.

The aim of this rapid review is to systematically review and evaluate the available evidence from published research, as well as to collate guidelines and recommendations in order to provide guidance on the management of urogynaecological conditions and clinical practices in response to the COVID-19 pandemic. This review has been undertaken by CHORUS, An International Collaboration for Harmonising Outcomes, Research and Standards in Urogynaecology and Women's Health (i-chorus.org).

\section{Materials and methods}

We performed a literature review using the OvidSP search platform and interrogating through this the databases PubMed/Medline, Embase and Cochrane using keywords and MeSH terms including: COVID-19, SARS-CoV-2, coronavirus, incontinence, pelvic organ prolapse, vaginal prolapse, uterine prolapse, cystocele, rectocele, bladder pain, childbirth trauma, perineal trauma, perineal laceration, urogynaecology, urogynecology, overactive bladder $(\mathrm{OAB})$, recurrent cystitis, recurrent urinary tract infections (UTIs); (Appendix 1).

Literature searches were conducted from 1 January to 22 September 2020. We searched the references of the relevant studies manually using the backward snowballing method [11] in order to identify additional eligible references and studies. In addition, a manual search was conducted of national and international specialist societies and organisations in order to identify practice guidance. We searched the websites of the International Urogynecological Association (IUGA), International Continence Society (ICS), European Association of Urology (EAU), British Society of Urogynaecology (BSUG), Royal College of Obstetricians and Gynaecologists (RCOG), Royal Australian and New Zealand College of Obstetricians and Gynaecologists (RANZCOG), American Urological Association (AUA), American Urogynecologic Society (AUGS), Asia-Pacific Urogynecology Association (APUGA), Urogynecologist Asia (UG-Asia), Urological Association of Asia (UAA), South African Urogynaecological Association (SAUGA) and Pan African Urological Association
(PAUSA). The latest version of guidelines was used in cases where more than one guideline or update was available. The final decision about the inclusion of guidelines and published articles was based on authors' consensus.

All searches were restricted to English-language publications or those with the facility to translate to English, guidelines and best-practice statements. We did not exclude original articles, comments or perspectives. Inclusion criteria were the presence in the articles of guidance or practical advice for the management of urogynaecology patients during the COVID-19 pandemic.

Exclusion criteria were non-English-language articles with translation not readily available, guidelines unavailable to the public in full text, not involving urogynaecology care or not involving urogynaecology care during the COVID-19 pandemic.

Study selection was conducted in stages. Following title screening, the abstracts of all articles in the database were examined. Two reviewers scrutinised the full text of each article and evaluated the studies potentially eligible for inclusion against the inclusion criteria. Discrepancies regarding inclusion or exclusion were resolved through discussion.

Ethical approval was not required for this review. One reviewer extracted relevant data from all eligible articles. The content of each guideline or article was tabulated including the title of the guidance or article, issuing association or journal, and date of publication.

The quality of guidelines was evaluated using the Appraisal of Guidelines for Research and Evaluation (AGREE II) instrument [12] and the quality of reviews assessed using Scale for the Assessment of Narrative Review Articles (SANRA) [13].

\section{Results}

Nine guidance documents and 17 articles, 10 of which are reviews, were included (Fig. 1; Table 1).

Quality assessment of guidelines was performed using Appraisal of Guidelines for Research and Evaluation II instrument (AGREEII). Overall assessment scores are shown in Table 1 (1 lowest quality to 7 highest quality). See Appendix 2 for individual domain scores.

Review articles were assessed using the Scale for the Assessment of Narrative Review Articles (SANRA) with a maximum score of 12. See Appendix 3 for the full SANRA scale.

\section{Recommendations}

All 12 articles and guidelines that included outpatient clinic recommendations stated that virtual clinics should be used to minimise horizontal transmission. Virtual clinics can be used for all non-urgent indications such as urinary incontinence and prolapse, and for both initial consultations and follow-up appointments. Patient satisfaction is unaffected and clinic attendance may be increased owing to a reduction in non-attendance [19]. 


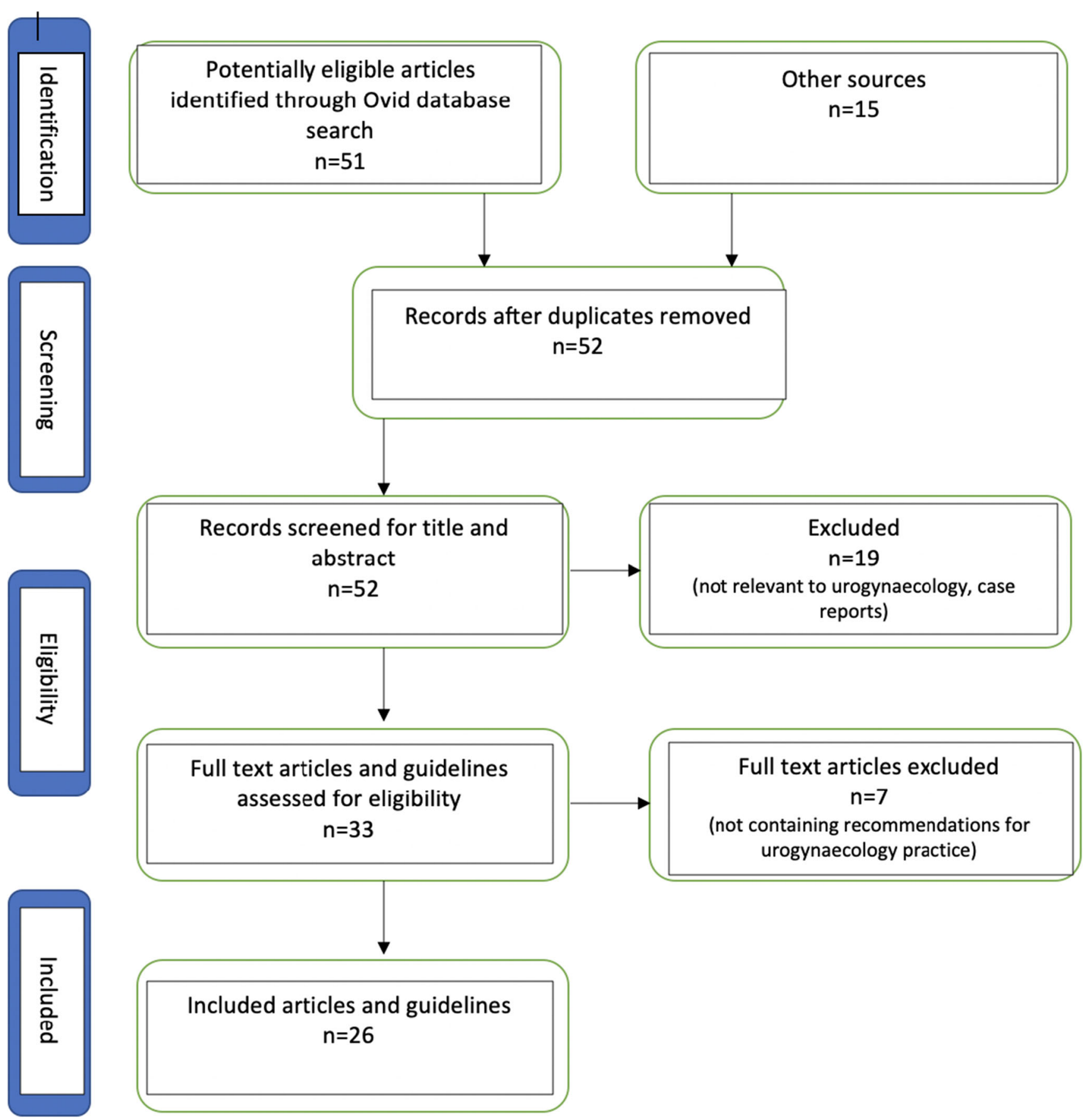

Fig. 1 Preferred Reporting Items for Systematic Reviews and Meta-Analyses (PRISMA) diagram

When used for postoperative follow-up there is no increase in adverse outcomes [19]. For patients awaiting surgery, virtual clinics can be conducted to rediscuss alternative therapies.

During virtual clinics, patients can be triaged and limited face-to-face appointments arranged if necessary. When seen face to face, appropriate screening should be undertaken, personal protective equipment (PPE) worn, physical distance maintained, and sanitation available [31].

It has been reported that COVID-19 transmission could be as high as $12.8 \%$ at a physical distance of less than $1 \mathrm{~m}$ compared with $2.6 \%$ at a distance of more than $1 \mathrm{~m}$, reflecting the importance of maintaining physical distance [34].

In keeping with these findings, the Scientific Advisory Group for Emergencies (SAGE), who provide scientific and technical advice to support government decision makers in the UK, reported that COVID-19 transmission could be 2-10 times higher at a physical distance of $1 \mathrm{~m}$ compared with $2 \mathrm{~m}$ [35]. See Table 2 for a summary of guidance for virtual clinics and inpatient admissions. 
Table 1 Included articles and guidelines

\begin{tabular}{|c|c|c|c|c|c|}
\hline Reference & Date & Title & Article type & Topics included & $\begin{array}{l}\text { Quality } \\
\text { assessment } \\
\text { score }\end{array}$ \\
\hline [14] & 23 March & $\begin{array}{l}\text { Urology practice during } \\
\text { the COVID-19 pandemic }\end{array}$ & Guidance & $\begin{array}{l}\text { Surgical prioritisation } \\
\text { Surgical techniques to minimise exposure } \\
\text { Outpatient procedures }\end{array}$ & 5 \\
\hline [2] & 26 March & $\begin{array}{l}\text { Joint RCOG/BSGE } \\
\text { Statement on gynaecological } \\
\text { endoscopy during the } \\
\text { COVID-19 pandemic }\end{array}$ & Guidance & $\begin{array}{l}\text { Laparoscopic and hysteroscopic surgery } \\
\text { Limiting horizontal spread of COVID-19 } \\
\text { Optimising patient outcomes }\end{array}$ & 4 \\
\hline [4] & 27 March & $\begin{array}{l}\text { Joint Statement on minimally } \\
\text { invasive gynecologic surgery } \\
\text { during the COVID-19 pandemic }\end{array}$ & Guidance & $\begin{array}{l}\text { Limiting horizontal spread of COVID-19 } \\
\text { Endoscopic surgery } \\
\text { Vaginal and open abdominal surgery }\end{array}$ & 5 \\
\hline [15] & 3 April & $\begin{array}{l}\text { COVID-19: outpatient services; } \\
\text { office consultations and } \\
\text { procedures }\end{array}$ & Guidance & Outpatient clinics and procedures & 4 \\
\hline [3] & 9 April & $\begin{array}{l}\text { BSUG guidance on management } \\
\text { of urogynaecological conditions } \\
\text { and vaginal pessary use during } \\
\text { the Covid } 19 \text { pandemic }\end{array}$ & Guidance & $\begin{array}{l}\text { Assessment and management of lower } \\
\text { urinary tract symptoms } \\
\text { Management of prolapse } \\
\text { Pessary management } \\
\text { Outpatient procedures }\end{array}$ & 5 \\
\hline [16] & 20 April & $\begin{array}{l}\text { COVID-19: recommendations } \\
\text { for functional urology }\end{array}$ & Guidance & $\begin{array}{l}\text { Assessment and management of lower } \\
\text { urinary tract symptoms } \\
\text { Management of prolapse } \\
\text { Outpatient procedures } \\
\text { Surgical prioritisation }\end{array}$ & 6 \\
\hline [17] & 28 April & $\begin{array}{l}\text { Guidance for the management } \\
\text { of urogynecological conditions } \\
\text { during the coronavirus } \\
\text { (COVID-19) pandemic }\end{array}$ & Guidance & $\begin{array}{l}\text { Assessment and management of lower } \\
\text { urinary tract symptoms } \\
\text { Management of prolapse } \\
\text { Post-operative follow-up }\end{array}$ & 6 \\
\hline$[18]$ & 28 April & $\begin{array}{l}\text { Joint Statement on re-introduction } \\
\text { of hospital and office-based } \\
\text { procedures in the COVID-19 } \\
\text { climate for the practicing } \\
\text { urogynecologist and gynecologist }\end{array}$ & Guidance & $\begin{array}{l}\text { Surgical prioritisation } \\
\text { Inpatient and outpatient procedures }\end{array}$ & 5 \\
\hline [5] & July & $\begin{array}{l}\text { An organisation-wide collaborative } \\
\text { effort to adapt the EAU } \\
\text { guidelines recommendations to } \\
\text { the COVID-19 era }\end{array}$ & Guidance & $\begin{array}{l}\text { Surgical prioritisation } \\
\text { Management of lower urinary tract } \\
\text { symptoms }\end{array}$ & 6 \\
\hline [19] & 27 April & $\begin{array}{l}\text { A guide for urogynecologic } \\
\text { patient care utilizing telemedicine } \\
\text { during the COVID-19 pandemic: } \\
\text { review of existing evidence }\end{array}$ & Review & $\begin{array}{l}\text { Virtual clinics } \\
\text { Management of lower urinary } \\
\text { tract symptoms } \\
\text { Management of prolapse } \\
\text { Pessary management }\end{array}$ & $12 / 12$ \\
\hline$[20]$ & 24 May & $\begin{array}{l}\text { Forecasting the future of urology } \\
\text { practice: a comprehensive review } \\
\text { of the recommendations by } \\
\text { international and European } \\
\text { associations on priority procedures } \\
\text { during the COVID-19 pandemic }\end{array}$ & Review & $\begin{array}{l}\text { Telemedicine } \\
\text { Prioritisation strategies for } \\
\text { oncological and non-oncological } \\
\text { urology procedures } \\
\text { Minimally invasive surgery }\end{array}$ & $11 / 12$ \\
\hline$[21]$ & 29 May & $\begin{array}{l}\text { Practical recommendations for } \\
\text { gynecologic surgery during } \\
\text { the COVID-19 pandemic }\end{array}$ & Review & Surgical prioritisation & $8 / 12$ \\
\hline$[22]$ & 17 June & $\begin{array}{l}\text { Guidance for gynecologists } \\
\text { utilizing telemedicine during } \\
\text { COVID-19 pandemic based } \\
\text { on expert consensus and } \\
\text { rapid literature reviews }\end{array}$ & Review & Telemedicine & $12 / 12$ \\
\hline [23] & 18 June & & Systematic review & Telemedicine & $12 / 12$ \\
\hline
\end{tabular}


Table 1 (continued)

\begin{tabular}{|c|c|c|c|c|c|}
\hline Reference & Date & Title & Article type & Topics included & $\begin{array}{l}\text { Quality } \\
\text { assessment } \\
\text { score }\end{array}$ \\
\hline & & $\begin{array}{l}\text { Telehealth in urology: a systematic } \\
\text { review of the literature. How } \\
\text { much can telemedicine be } \\
\text { useful during and after the } \\
\text { COVID-19 pandemic? }\end{array}$ & & $\begin{array}{l}\text { Management of lower urinary } \\
\text { tract symptoms }\end{array}$ & \\
\hline \multirow[t]{3}{*}[8]{} & \multirow[t]{3}{*}{23 June } & \multirow{3}{*}{$\begin{array}{l}\text { COVID-19 and gynecological } \\
\text { cancer: a review of the } \\
\text { published guidelines }\end{array}$} & \multirow[t]{3}{*}{ Review } & $\begin{array}{l}\text { Reducing horizontal transmission } \\
\text { Surgical prioritisation }\end{array}$ & \multirow[t]{3}{*}{$11 / 12$} \\
\hline & & & & Outpatient clinics & \\
\hline & & & & Inpatient admissions & \\
\hline$[24]$ & 9 July & $\begin{array}{l}\text { Triaging office based urology } \\
\text { procedures during the } \\
\text { COVID-19 pandemic }\end{array}$ & Recommendations & Outpatient procedures & \\
\hline \multirow[t]{3}{*}[25]{} & \multirow[t]{3}{*}{25 August } & \multirow{3}{*}{$\begin{array}{l}\text { How did COVID- } 19 \text { pandemic } \\
\text { change the way we attend } \\
\text { the patients in an } \\
\text { urogynaecological unit }\end{array}$} & \multirow[t]{3}{*}{ Review } & $\begin{array}{l}\text { Assessment and management of } \\
\text { lower urinary tract symptoms } \\
\text { Management of prolapse }\end{array}$ & \multirow[t]{3}{*}{$9 / 12$} \\
\hline & & & & Surgical prioritisation & \\
\hline & & & & Telemedicine & \\
\hline$[26]$ & 2 September & $\begin{array}{l}\text { A lasting impression: telemedicine } \\
\text { in urogynecology during the } \\
\text { coronavirus disease } 2019 \\
\text { pandemic }\end{array}$ & Review & Telemedicine & $10 / 12$ \\
\hline \multirow[t]{2}{*}[27]{} & \multirow[t]{2}{*}{15 September } & \multirow{2}{*}{$\begin{array}{l}\text { A systematic review on guidelines } \\
\text { and recommendations for } \\
\text { urology standard of care during } \\
\text { the COVID-19 pandemic }\end{array}$} & \multirow[t]{2}{*}{ Review } & $\begin{array}{l}\text { Uro-oncology } \\
\text { Endoscopic and robotic surgery }\end{array}$ & \multirow[t]{2}{*}{$12 / 12$} \\
\hline & & & & Outpatient procedures & \\
\hline \multirow[t]{2}{*}[28]{} & \multirow[t]{2}{*}{15 September } & \multirow[t]{2}{*}{$\begin{array}{l}\text { Management of female and } \\
\text { functional urology patients } \\
\text { during the COVID pandemic }\end{array}$} & \multirow[t]{2}{*}{ Review } & $\begin{array}{l}\text { Surgical prioritisation } \\
\text { Surgical techniques to minimise } \\
\quad \text { exposure }\end{array}$ & \multirow[t]{2}{*}{$11 / 12$} \\
\hline & & & & $\begin{array}{l}\text { Management of lower urinary tract } \\
\text { symptoms }\end{array}$ & \\
\hline$[29]$ & March & $\begin{array}{l}\text { Resumption of elective surgery } \\
\text { following COVID-19 outbreak, } \\
\text { guideline for female pelvic } \\
\text { medicine and surgery }\end{array}$ & Editorial & Surgical prioritisation & \\
\hline$[30]$ & 1 June & $\begin{array}{l}\text { Global challenges to urology } \\
\text { practice during the } \\
\text { COVID-19 pandemic }\end{array}$ & Comment & Surgical prioritisation & \\
\hline$[31]$ & 11 June & $\begin{array}{l}\text { Technology-based management } \\
\text { of neurourology patients in the } \\
\text { COVID-19 pandemic: is this } \\
\text { the future? A report from the } \\
\text { International Continence Society } \\
\text { (ICS) institute }\end{array}$ & & Virtual clinics & \\
\hline \multirow[t]{2}{*}[18]{} & \multirow[t]{2}{*}{1 July } & \multirow{2}{*}{$\begin{array}{l}\text { Widespread postponement of } \\
\text { functional urology cases } \\
\text { during the COVID-19 pandemic: } \\
\text { rationale, potential pitfalls, and } \\
\text { future consequences }\end{array}$} & \multirow[t]{2}{*}{ Editorial } & \multirow{2}{*}{$\begin{array}{l}\text { Assessment and management of } \\
\text { incontinence and voiding } \\
\text { disorders } \\
\text { Management of prolapse }\end{array}$} & \\
\hline & & & & & \\
\hline$[32]$ & 2 July & $\begin{array}{l}\text { Virtual consent for virtual patients: } \\
\text { benefits of implementation in a } \\
\text { peri- and post-COVID-19 era }\end{array}$ & Editorial & Virtual clinic and consent & \\
\hline \multirow[t]{2}{*}[33]{} & \multirow[t]{2}{*}{17 July } & \multirow{2}{*}{$\begin{array}{l}\text { Neuro-urology during the } \\
\text { COVID-19 pandemic: triage } \\
\text { and priority of treatments }\end{array}$} & \multirow[t]{2}{*}{ Letter to editor } & \multirow{2}{*}{$\begin{array}{l}\text { Voiding dysfunction } \\
\text { Neurogenic bladder }\end{array}$} & \\
\hline & & & & & \\
\hline
\end{tabular}

RCOG Royal College of Obstetricians and Gynaecologists, BSGE British Society for Gynaecological Endoscopy, AUGS American Urogynecologic Society, RANZCOG Royal Australian and New Zealand College of Obstetricians and Gynaecologists, BSUG British Society of Urogynaecology, EAU European Association of Urology 
Table 2 Summary of guidance for virtual clinics and inpatient admissions

Reference Virtual clinics/telemedicine

Outpatient department, inpatient admissions

[17] Postoperative follow-up can be virtual

Non-inferior for patient satisfaction, complication rates and adverse events

[31] Cancel all face-to-face outpatient appointments

Virtual consultations where possible

Can identify patients requiring urgent consultation

[28] Initial and follow-up consultations can be virtual

Triage patients for face-to-face consultation

[19] Virtual clinics: patient satisfaction unaffected, can increase clinic attendance

Postoperative virtual clinics: no increase in adverse outcomes or primary care visits

Native tissue prolapse repair and mid-urethral sling with no incontinence can be safely followed up in virtual clinic

Triage all patients for virtual clinic: established patients not requiring examination, new patients who would benefit from non-surgical treatment, postponed patients awaiting surgery to rediscuss alternative therapies

Provide patient information leaflets from established bodies

[8] Virtual clinics

Physical distancing

Sanitisation areas

Work from home

Minimise face-to-face

Limit friends and family accompanying

Adequate PPE

[3] Virtual clinic for pessary follow-up

Triage patients: see semi-urgently, within 30 days or delayed review

[16] Use telemedicine

Avoid face-to-face where possible

[26] Telemedicine to minimise exposure

[22] Use telemedicine

Avoid face-to-face where possible

Use telemedicine to assess need for face-to-face review

Postoperative follow-up: equal patient-related outcomes with telemedicine compared with face-to-face

[36] Use video or teleconsults for all non-urgent indications

[5] Use telemedicine to allow physical distancing and minimise footfall

[18] Telemedicine whilst awaiting surgery to help with symptom management

Essential staff only in clinic rooms

Discourage accompanying persons

Physical distancing

Cleaning surfaces with appropriate disinfectant

Handwashing before and after patient contact

Waiting and clinic room with appropriate safe spacing

COVID-19 positive or those in isolation should not be seen face-to-face. If no option, then wear appropriate PPE

If face-to-face appointment, screen all patients and accompanying persons for symptoms, travel and exposure

$P P E$ personal protective equipment 
Table 3 Summary of guidance for urinary incontinence and prolapse

\section{Reference OAB, UUI and SUI}

[17] Virtual consultations

Use validated questionnaires for urinary symptoms

Lifestyle measures, PFMT as first line

Consider starting antimuscarinics/B3 agonist/vaginal oestrogen

Regular follow-up, i.e. 4 weeks after starting antimuscarinics

Yearly review of long-term antimuscarinic

For SUI consider incontinence pessaries

[33] For neurogenic SUI: device implantation can be deferred until safe, no time limit, use pads in interim

Erosion from implants requiring removal of prosthesis: defer up to 4 weeks

Neurogenic bladder with risk factors for upper renal tract, e.g. DSD: Botox can be deferred up to 8 weeks

Neurogenic bladder without risk factors for upper renal tract: can defer Botox during pandemic, no time limit

[31] Can teach and monitor PFMT via video consultation

[28] Delay all continence procedures until after COVID crisis

Manage as outpatients with conservative and medical therapy

Delay all new sacral neuromodulation until end of COVID crisis

Remove percutaneous nerve evaluation lead in outpatient clinic if one in situ

If infected implant treat with intravenous antibiotics; if severe infection remove urgently, i.e. $<2$ weeks

Conservative and medical treatments for SUI and OAB/UUI

[27] Stage 2 neuromodulation: no delay owing to risk of infection

[19] Behavioural measures

Self-inserted incontinence tampons or pessaries can be recommended

Patients having invasive treatment, e.g. intravesical Botox, can restart antimuscarinic/mirabegron until service restarts

Short-term antimuscarinic unlikely to cause dementia therefore can use in elderly if required

\section{Initial virtual consultations}

Can commence treatment remotely

Provide patients with information resources

[16] Encourage conservative and medical treatments
Prolapse and pessaries

Virtual consultations

Use validated questionnaires for prolapse

If mild symptoms: PFMT

If severely affecting bladder/bowel function and/or ulcer present, may require face-to-face appointment

Pessaries: arrange face-to-face if bleeding or pain symptoms

Can delay pessary change for an additional 3 months after routine 6-month interval, then review

Pessary changes: defer for 3-6 months

Virtual consultations

Online instructions for PFMT

Behavioural measures, e.g. weight loss, Kegel exercises, PFMT

Smart phone apps, e.g. for Kegel training

Home biofeedback devices

Pessaries: encourage self-cleaning at home

Can safely delay change up to 6 months

Consider vaginal oestrogen and empiric treatment for bacterial vaginosis

If bleeding/discharge can remove and observe for voiding dysfunction prior to clinic review

Initial virtual consultations

Procidentia causing bowel/urinary problems need early review within 30 days

Pessaries: face-to-face review within 7 days if symptoms suggestive of fistulation

Pessaries: face-to-face review within 30 days if bleeding/pain/ulceration

Pessaries: refer via local PMB cancer pathway if PMB with pessary and uterus in situ

Ring pessaries: can defer change up to 6 months

Shaatz, shelf, Gelhorn, double pessaries: defer for a maximum of 3 months

Patients to be given contact numbers in the case of symptoms of ulceration

Virtual clinics 
Table 3 (continued)

Reference OAB, UUI and SUI

Prolapse and pessaries

SUI: all new patients with signs of retention and overflow, see face-to-face for If grade 4 prolapse, consider US KUB PVR with external probe

[26] Non-surgical options as first line whilst elective surgeries restricted

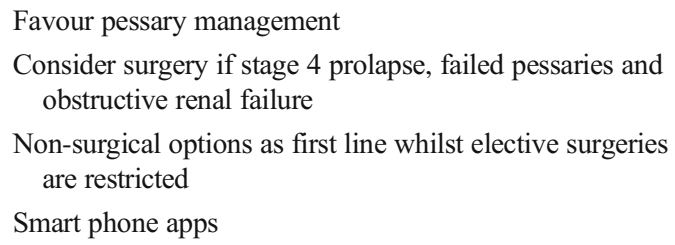
obstructive renal failure

Non-surgical options as first line whilst elective surgeries are restricted

Smart phone apps

Medication management

Smart phone apps

[25] Start all UI consultations using telemedicine

Supplement with use of mobile apps

Conservative measures - weight loss, bladder training, PFMT, Kegel exercises \pm medications

[36] Prescribe medication if required, all intravesical Botox postponed

PFMT postponed to maintain physical distancing

Screen for red flag symptoms that may indicate bladder cancer and warrant urgent cystoscopy

Postpone SNS unless in test phase. If test phase, consider removal or placement of pacemaker under local anaesthesia

[21] Use non-surgical management UI as advised by IUGA

[23] Evidence that behavioural measures and PFMT via video conferencing as effective as face-to-face

[5] Use conservative and medical treatments

PFMT postponed to maintain physical distancing

Use pessary

Urgent surgery if grade 4 prolapse/renal tract complications and failed pessaries

Use of behavioural measures and PFMT

Can delay pessary change up to 3 months if no erosion or ulcer

$B S U G$ British Society of Urogynaecology, EAU European Association of Urology, OAB overactive bladder, UUI urge urinary incontinence, SUI stress urinary incontinence, $P F M T$ pelvic floor muscle training, $D S D$ detrusor sphincter dyssynergia, $P V R$ post-void residual volume, $U I$ urinary incontinence, $S N S$ sacral nerve stimulation, IUGA International Urogynecological Association, US KUB ultrasound kidneys, ureters and bladder, $P M B$ postmenopausal bleeding

Of 15 articles and guidelines providing recommendations regarding the management of urinary incontinence and $\mathrm{OAB}$, 12 advise behavioural therapies as the first line.

Two recommend use of smart phone apps to supplement education, for example, for Kegel exercises [19, 26]. Suspension of invasive therapies for urinary incontinence is advised, except where stage 1 sacral neuromodulation is in place or in cases of neurogenic bladder with a high risk of upper renal tract complications [33]. Pelvic floor muscle training is recommended as the first-line for symptomatic prolapse $[16,17,19,23$, 26]; however, in one editorial, suspension of pelvic floor muscle training is suggested to maintain physical distancing [36].

Use of pessaries is recommended, whilst prolapse surgery is deferred $[16,26,36]$, and the pessary change interval can be extended by $3-6$ months unless the patient has symptoms of ulceration or fistulation $[3,24,27]$. See Table 3 for a summary of guidance for urinary incontinence and prolapse.

Acute retention or a blocked catheter warrants urgent review for catheterisation [20].

If an indwelling catheter is in situ, routine changes can be deferred for 2-4 weeks, unless the patient has a history of difficult changes or recurrent UTIs [24]. Deferring suprapubic catheter changes $[3,20]$ for up to 3 months has been suggested and changes in the community rather than in the hospital setting are preferred $[3,36]$.

Urinary tract infections can be managed via virtual consultation $[17,19,23,25]$. If the patient has recurrent UTIs conservative measures and non-antibiotic therapies should be encouraged [17]. If antibiotics are required, they should be prescribed according to previous culture results. Face-to-face review should be arranged if the patient has complicated UTI or is refractory to treatment [19]. See Table 4 for a summary of voiding dysfunction and urinary tract infection.

Gross haematuria requires urgent investigation with cystoscopy; however, microscopic haematuria investigations can be deferred. A systematic review of telemedicine in urology, however, reported that data indicate that virtual clinics for initial evaluation are feasible, effective, and associated with a high degree of patient satisfaction [23].

Bladder pain syndrome investigations should be deferred, but oral treatments can be started [5, 28].

Fourteen articles reported recommendations for outpatient procedures, including cystoscopy, intravesical Botox and 
Table 4 Summary of voiding dysfunction and urinary tract infection

Reference Voiding dysfunction and catheters Urinary tract infection

[17] Severe voiding difficulty requires face-to-face appointment for $\mathrm{PVR} \pm \mathrm{ISC}$

[33] If chronic retention, no limit on deferral

IDC if ISC not available

[31] Can teach and monitor ISC via video consultation

[28] If acute retention, see face-to-face to assess for IDC or SPC \pm US KUB. Delay functional tests

Indwelling catheter: can defer by 4 weeks. Change earlier if encrustations/blockages

[24] IDC: can defer change for 2-4 weeks unless history of difficult changes or recurrent UTI

[19] Encourage conservative measures to help void

Chronic retention $>300 \mathrm{ml}>6$ months and acute retention: face-to-face review

CISC preferable to IDC

[20] Acute retention: see face-to-face

Defer all SPC and IDC changes

[14] Acute retention: see face-to-face for IDC or SPC

[3] If acute retention need emergency/urgent review (within 12 hours) for IDC

If arranging TWOC, can defer on a case-by-case basis. If high PVR, then teach CISC

Change of SPC can be delayed up to 3 months

Aim for SPC change in community not hospital setting

[25] Encourage conservative measures to help void, e.g. double/triple voiding

Chronic urinary retention, e.g. $>300 \mathrm{ml}$ for $>6$ months, consider USS KUB and face-to-face consultation for ISC or IDC

ISC preferable to IDC

Teach ISC face-to-face, follow-up via virtual clinic

[36] Acute retention: place IDC or SPC, change regularly in the community. Consider ISC if teaching and education possible

[30] Obstructive urinary disorders - face-to-face clinics with reduced capacity

[5] Voiding dysfunction: teach ISC or catheterise

Blocked catheter requires emergency review

[23]
Virtual consultations

Acute UTI: consider antibiotics based on symptoms and previous cultures

For recurrent UTI: non-antibiotics therapies, fluid advice, hygiene advice, vaginal oestrogen low dose. Self start or rotating antibiotics. Safety net re: ascending infection

Conservative and lifestyle measures: hygiene, non-antibiotics therapies, low-dose antibiotics, vaginal oestrogen

Culture with every episode and treat whilst awaiting results

Previous cultures can guide prescribing

Remote prescribing effective, may have a negative impact on antibiotics resistance. Fever and diabetes can indicate severe infection, may warrant face to face appointment

Prescribing: nitrofurantoin or cotrimoxazole 3-7 days. Seven-day course for the elderly and diabetic. Fluoroquinolone in complicated UTI to avoid admission

Encourage conservative measures, e.g. cranberry, hydration, d-mannose, vaginal oestrogen

Consider face-to-face review if refractory UTI with complications
Empirical treatment of UTI, including recurrent UTI

Electronic prescribing is effective and efficient

Resolution of symptoms indicative of cure

Sepsis/complicated UTI: high priority

Can be managed safely and effectively using telemedicine

$B S U G$ British Society of Urogynaecology, EAU European Association of Urology, $P V R$ post-void residual volume, ISC intermittent self-catheterisation, $I D C$ indwelling urethral catheter, SPC suprapubic catheter, US KUB ultrasound of the kidneys, ureters and bladder, UTI urinary tract infection, CISC clean intermittent self-catheterisation, TWOC trial without catheter 
Table 5 Summary of guidance for haematuria, bladder pain syndrome and outpatient procedures

Reference Haematuria and bladder pain syndrome

Outpatient procedures

[17] Referral to secondary care if gross haematuria

[24] Gross haematuria: urgent cystoscopy, no deferring

Delay urodynamics for 3-6 months

Microscopic haematuria with risk factors: can defer for up to 3 months unless symptomatic

Microscopic haematuria and no symptoms: can defer for 3 months or more

[27] Most but not all experts recommend urgent cystoscopy for macroscopic haematuria. EAU and USANZ say it can be deferred for 1-2 months

[20] Macroscopic haematuria: urgent cystoscopy

Microscopic: postpone

[23] Use telemedicine for initial haematuria consult and triage, then see face-to-face if needed

[30] Continue cystoscopy for suspected cancer

[28] Delay BPS investigations until after COVID

Use oral medications, e.g. amitriptyline

Continue bladder instillation if self-administered already

Defer if administered in hospital

[19] Consider face-to-face review if acute BPS flare requiring instillation

[5] Manage BPS conservatively

Can offer amitriptyline

Delay urodynamics. Time frame 1-6 months

Neurogenic intravesical Botox can be deferred for up to 4 weeks Slings: clinical harm unlikely if postponed for 6 months

Defer all cystoscopy for benign conditions

All outpatient cystoscopy suspended, continue only for suspected cancer

Do not commence new intravesical Botox treatments

Delay intravesical Botox until end of COVID crisis

All urodynamics postponed

All urodynamics postponed

Intravesical Botox can be carried out under local anaesthetic for high-risk patients, e.g. autonomic dysreflexia

Defer all cystoscopy for benign conditions

Defer all outpatient treatments and investigations, i.e. cystoscopy (non-cancer indications), bladder instillations, PTNS

Intravesical Botox suspended unless neurological bladder with upper tract risk

Cystoscopy: perform within 2 months if risk factors for cancer and refractory $\mathrm{OAB}$

If planned intravesical Botox, can defer and restart antimuscarinics/B3 agonists

Intravesical Botox postponed. Consider continuing under local anaesthesia for neurogenic bladder with renal tract complications

Intravesical Botox: non-essential, i.e., not time sensitive unless, e.g. failure of conservative and progressive symptoms

Tier 1 can delay beyond 12 weeks i.e. new Botox, new bulking, new PTNS, urodynamics, pessary fittings, new PFMT

Tier 2 delay 4-12 weeks, e.g. repeat bulking agent, pessary cleaning, PFMT follow-up

Tier 3 delayed for up to 4 weeks

Microscopic haematuria, established PTNS, bladder instillations

Tier 4 cannot be delayed

Macroscopic haematuria, new ISC instruction, voiding trial, urinary retention, SPC follow-up

$E A U$ European Association of Urology, BSUG British Society of Urogynaecology, USANZ Urological Society of Australia and New Zealand, BPS bladder pain syndrome, $P T N S$ percutaneous tibial nerve stimulation, $O A B$ overactive bladder, $P F M T$ pelvic floor muscle training, ISC intermitten selfcatheterisation 
Table 6 Summary of guidance for elective surgery and techniques to minimise horizontal transmission

$\begin{aligned} & \text { Title of } \\ & \text { article or }\end{aligned}$
Elective surgery and consent
article or guidance

[2]

$[28]$

[20] Route of surgery at surgeon's discretion

[14] Experienced surgeon to minimise operating time Clinical trials and trials of new technology to be postponed COVID test all patients preoperatively

Temperature testing and wearing masks on arrival

Reduce inpatient beds to allow physical distancing

[4] Suspend all elective surgery

Universal COVID-19 testing recommended before all surgery

Temperature on admission, defer if $\geq 37.3^{\circ} \mathrm{C}$ and retest after 14 days

Negative pressure in theatre

High frequency of filtered air exchange

Essential theatre staff only

Most experienced surgeon operating

PPE when GA: water repellent, long-sleeved gowns, eye and face protection, gloves and FFP3 respirators

prexial within 30 days screen and retest for COVID-19

Special care to be taken with laparoscopic and robotic procedures

Consider local anaesthesia where possible to minimise AGPs

local guidelines and availability

Most surgery is priority level 4 and can be deferred over 3 months
No evidence of increased risk with laparoscopy when PPE worn Vacuum suction devices for desufflation Use smoke extractor

Avoid long desiccation times

Closed smoke evacuation/filtration system with ULPA capability

Laparoscopic suction to remove smoke and deflate abdomen

Low intra-abdominal pressure $10-12 \mathrm{mmHg}$ if feasible

Avoid rapid deflation

Minimise blood/fluid droplet spread

Be careful at time of instrument exchange and tissue extraction

Minimise $\mathrm{CO}_{2}$ leakage from trocars

Endoscopic and robotic surgery: low electrocautery settings to generate less smoke, lowest pressure insufflation, only essential staff present in theatre, all staff in PPE

Use closed system for insufflation

Smoke extractor

Adequate PPE

Use lowest intrabdominal pressure possible

Use lowest cautery setting possible

Shorter hospital stay

Can physical distance more than in open surgery

Risk of COVID transmission if not operating on GI tract during laparoscopy is low

Low power diathermy. Closed smoke evacuation

Filtration system

Use suction to deflate abdomen

Low pressure 10-12 mmHg intraoperatively

Avoid rapid desufflation, minimise blood or fluid spray

Check seals around all reusable ports

GA in negative pressure room

Filter system to reduce viral release with gas

Low pressure pneumoperitoneum

Low bipolar cautery setting

Low intra-abdominal pressure 10-12 $\mathrm{mmHg}$

Low power settings for electrosurgical devices 
Table 6 (continued)

Title of article or guidance
Surgical techniques to minimise horizontal transmission
Preoperative screening on day of surgery, i.e. history examination

Full PPE in theatre - shoe covers, impermeable gowns, surgical or N-95 masks, protective head covering, gloves and eye protection

Restricted movement of personnel in and out of the operating room

Trainee participation should be limited and include only essential personnel

[16] Enhanced recovery

[30] Only urgent procedures to minimise inpatient stays

Screening consultation prior to procedure - symptoms in last 2 weeks, any travel

Test patients and clinical team prior to procedure

Positive pressure on hold during procedure and restarted $20 \mathrm{~min}$ after patient leaves

Limited personnel in theatre

$[5]$

[31]

[19]
Recommend only high priority/emergency cases, experienced surgeon

Minimal staff numbers, no observers

Intubation and extubation in negative pressure room

Use low cautery settings

Avoid monopolar or advanced bipolar where possible

If monopolar use smoke evacuator

No clear evidence to favour open or laparoscopic

Consider treating intermediate priority patients if capacity available but not during COVID surge

Follow local recommendations to test staff and patients for COVID

Follow local recommendations for PPE

Wear full PPE for COVID-positive patients as per WHO guidance

All invasive procedures under GA deferred

All elective cases deferred

Aim for same-day discharge where possible

Spinal anaesthesia in preference to general anaesthesia, unlikely to greatly increase voiding dysfunction

Transmission of fomites during vaginal surgery appears highly unlikely

Regional anaesthesia preferable to general anaesthesia-lower risk postoperative retention, reduces aerosol generation

Augmentation cystoplasty, cystectomy, and continent and incontinent diversions all postponed owing to high-dependency in-patient care required
Avoidance of long desiccation times

Closed smoke evacuation or filtration system with ultra-low particulate air filtration capability

Suction desufflation of abdomen

Avoid rapid desufflation, i.e. with specimen removal

Minimise $\mathrm{CO}_{2}$ leakage from trocars

Minimise blood/fluid droplet spray

Vaginal and open surgery: non-electrosurgical techniques where possible

Low power setting, avoidance of long desiccation times

Smoke evacuators alongside ULPA filters

Suction device to remove surgical plume

Minimize blood/fluid droplet spray or spread

Limit intra-abdominal pressure

Balloon trocars to minimize $\mathrm{CO}_{2}$ leak

Smoke extractors

Suction of $\mathrm{CO}_{2}$ for desufflation

Safety of minimally invasive surgery remains undetermined

Low insufflation pressure

Suction of gas prior to removing ports

Smoke evacuation system capable of filtering aerosolized particles from $\mathrm{CO}_{2}$ should be provided for laparoscopic surgery 
Table 6 (continued)

\begin{tabular}{ll}
$\begin{array}{l}\text { Title of } \\
\text { article or } \\
\text { guidance }\end{array}$ & Elective surgery and consent \\
\hline$[21]$ & $\begin{array}{l}\text { Screen all patients with health questionnaire } \\
\text { Swab test before all elective surgery } \\
\text { All team members trained in appropriate use of PPE } \\
\text { Reduce all team members in theatre } \\
\text { If COVID positive, operate once fully recovered, i.e. asymptomatic } \\
\text { and two negative tests at 24-h interval } \\
\text { Ideal is virtual consultation with electronic consent including } \\
\text { pre-printed information and patient's electronic signature } \\
\text { Requires development with GMC and MHRA } \\
\text { Consent signed on day of procedure may lead to inadequate } \\
\text { consent and litigation }\end{array}$
\end{tabular}

$R C O G$ Royal College of Obstetricians and Gynaecologists, BSGE British Society for Gynaecological Endoscopy, EAU European Association of Urology, PPE personal protection equipment, GA general anaesthesia, AGP aerosol-generating procedure, GMC General Medical Council, $M H R A$ Medicines and Healthcare Products Regulatory Authority, ULPA ultra-low particulate air, GI gastrointestinal, WHO World Health Organisation

urodynamics. All urodynamics and cystoscopy for benign indications should be deferred. See Table 5 for a summary of guidance for haematuria, bladder pain syndrome and outpatient procedures.

Recommendations regarding surgery advise regional or local anaesthesia where possible, in order to reduce aerosol generation with general anaesthesia $[2,19,25,28]$. Screening for COVID-19 symptoms and testing preoperatively is advised, as evidence has shown poorer surgical outcomes for asymptomatic COVID-19 patients, therefore surgery may worsen or accelerate progression [2, 4, 5, 8, 14, 21, 28, 30]

Although better able to maintain physical distance and potentially shorter hospital stays with laparoscopic surgery than with open surgery [8], no evidence is available to support a specific route of surgery; therefore, this is at the surgeon's discretion [5, 20].

Recommendations to reduce horizontal transmission in surgery include having essential staff only in theatre, low electrocautery settings, closed smoke evacuation and minimising blood and fluid droplet spray [4, 5, 8, 14, 16, 20, $27,28]$. See Table 6 for a summary of guidance for elective surgery and techniques to minimise horizontal transmission.

Continuing or restarting surgery during the pandemic requires prioritisation of cases, taking into account the severity of the pathology, patient comorbidities and the impact on physical and mental health and quality of life. Seven documents specified prioritisation guidance. See Table 7 for a summary of the prioritisation of surgery.

\section{Strengths}

We followed a standardised rapid review methodology in order to provide a summary of recommendations and practice guidelines in a timely manner. We performed a comprehensive literature search including published articles, articles in press and association guidelines to ensure that we identified and included all available evidence regarding management of urogynaecology patients during the COVID-19 pandemic.

There is a high degree of consensus regarding the use of virtual clinics, management outpatient procedures, and surgical techniques to minimise horizontal transmission of COVID-19.

However, variations in recommendations exist and are summarised in this review. Therefore, it can be used as a resource to support adjustments in practice as local conditions evolve.

As further evidence emerges, resources change and the pandemic continues, this synthesis of available guidance can be used as a reference for clinicians to guide management.

\section{Limitations}

Given the aim to issue a summary without delay using rapid review methodology, some studies may have been omitted, which is an inherent limitation of rapid reviews. There is susceptibility to bias in streamlining a systematic review process, for example, in choosing studies for inclusion or exclusion and in data extraction, as fewer independent reviewers conduct each step.

Recommendations are predominantly based on expert opinion and, given the rapidly evolving nature of the COVID-19 virus, there is often a lack of robust scientific evidence [8] for clinically relevant questions.

Indeed, the COVID-19 "infodemic" has been described by WHO as an "overabundance of information-some accurate and some not - that occurs during an epidemic" [37]. 
Table 7 Summary of prioritisation of surgery

Reference Prioritisation of surgery

[28] Emergency $<1 \mathrm{~h}$ : life-threatening emergencies

Urgent $<24 \mathrm{~h}$ : e.g. haemorrhage after functional urology surgery, urinary retention, unable to place catheter, surgical site or device infection

Urgent elective $<4$ weeks: e.g. second stage of SNS, disabling refractory BPS, Botox in high-risk neurogenic bladder patients, urinary diversion in urinary fistula with severe complications

Elective, intermediate priority, 1-3 months: e.g. Botox in low-risk neurogenic bladder, bladder outlet obstruction due to mesh, removal of vaginally extruded uninfected mesh, prolapse with complications, e.g. retention, hydronephrosis

Elective, low-priority, >3 months: e.g. refractory OAB, elective SUI surgery, BPS, elective prolapse surgery, urethral diverticulum without complications, uncomplicated neurogenic bladder

[8] 1a: emergency $<24 \mathrm{~h}$ to save life

1b: urgent $<72 \mathrm{~h}$ as life-threatening condition

2: is required within $<4$ weeks with expectation of cure

3: can defer for 10-12 weeks with no predicated negative outcome

Enhanced recovery pathways: delay any oncology surgery by at least 15 days if COVID-19 symptoms preoperatively

[16] A: continue, e.g. second-stage neuromodulation, intravesical Botox for neurogenic bladder with risk of high bladder pressure, surgery for grade 4 prolapse with acute renal failure and failed pessary

B: 1-8 weeks, e.g. refractory $\mathrm{OAB}$ and bladder cancer risk factors

C: delay 8-16 weeks, e.g. intravesical Botox

D: can be delayed $>16$ weeks, e.g. stress urinary incontinence surgery

[29] 1: urgent, $<1$ month - delay could cause major harm, e.g. prolapse beyond hymen with voiding dysfunction or upper renal tract complications

2: essential elective, $<3$ months - increased risk of adverse outcomes if delayed for undetermined time period, e.g. prolapse beyond hymen with progressive symptoms, impaired QoL, failed pessaries but no upper renal tract complications

3: non-essential elective, postpone up to 1 year - not time sensitive, e.g. prolapse beyond hymen with no upper renal tract complications and able to use pessary

Continence surgery: non-essential elective, unless failure of conservative and progressive symptoms

[21] Category 1: urgent: within 30 days, potential to deteriorate and become an emergency

Category 2: semi-urgent: within 60 days, causes pain dysfunction or disability, but unlikely to deteriorate quickly, unlikely to become an emergency

Category 3: elective: within 365 days, causes pain dysfunction or disability, unlikely to deteriorate quickly, does not have potential to become emergency

All urogynaecology cases are category 3 , should be postponed. Can start in highly symptomatic patients when risk of transmission reduces, depending on local situations

[5] Low priority: clinical harm very unlikely if postponed for 6 months, e.g. stress or urge incontinence surgery, surgery for urethral diverticula Intermediate: clinical harm possible if postponed for 3-4 months but unlikely, e.g. surgical management of patients with urinary retention, intravesical Botox for selected cases of neurogenic bladder

High priority: clinical harm likely if postponed for over 6 weeks, e.g. cystoscopy for macroscopic haematuria

Emergency: life-threatening situation and likely to have presented in ED despite pandemic

[18]

Tier 1: non-life-threatening illness, low acuity, i.e. SUI surgery, laparoscopic sacrocolpopexy, native tissue transvaginal prolapse surgery, asymptomatic mesh exposure

Tier 2: non-life-threatening, but potential for near future morbidity or mortality, intermediate acuity, i.e. fistula repair, mesh-related complication, e.g. severe pain/infection

Tier 3: high potential for near future morbidity or mortality, severe impairment of QoL, high acuity, i.e. prolapse with upper tract obstruction and unable to retain pessary, obstructed voiding after MUS

Tier 4: emergency surgery

Each tier has subsets A and B

Subset B denotes patients with comorbidities that may be deferred until after lower acuity patients

$E A U$ European Association of Urology, BPS bladder pain syndrome, $O A B$ overactive bladder, SUI stress urinary incontinence, $E D$ emergency department, MUS mid-urethral sling, QoL Quality of life 
This is an inherent limitation of all reviews in this area given the unprecedented public health crisis and the epidemiological characteristics of the current pandemic.

As the COVID-19 pandemic continues, and our understanding and resources change, there is high potential for modifications within recommendations and publication of further guidance, which may have already occurred during publication of this rapid review.

\section{Conclusion}

The COVID-19 pandemic has changed the way in which we conduct healthcare and will do so for the foreseeable future. Evidence suggests that a large proportion of urogynaecological conditions might be able to be managed using virtual consultations utilising behavioural measures, lifestyle changes and medical therapy. Outpatient procedures in one-stop clinics to investigate and treat conditions such as refractory $\mathrm{OAB}$ can be maximised to avoid inpatient admissions, and to reduce the frequency of visits and the use of general anaesthesia.

Technology is required to maintain and develop the quality of virtual consultations and this is particularly important for remote teaching of clean intermittent self-catheterisation, home trial without catheter, pessary management and triaging symptoms. For those unable to use or without access to the required technology, smaller ad hoc face-to-face clinics with PPE and physical distancing should be considered.

Various healthcare providers and organisations have developed and published guidance for practice, which should always be observed, as it is linked and adapted to local policies, sociodemographic and epidemiological conditions, as well as infrastructures. This review is aimed at providing a wider perspective on practice recommendations that have been published to date and can be adapted or even considered for implementation at local levels.

Although adaptations and provisions are being made to manage urogynaecological conditions, given that the majority of patients are elderly with comorbidities that increase risk of COVID-19 morbidity and mortality, and with most surgical procedures for quality of life, the resumption of elective activity is expected to be slow. Consequently, there is likely to be a significant impact on quality of life within this cohort of patients and the impact of delayed diagnosis and treatment on the trajectory of the disease is yet to be determined.

Supplementary information The online version contains supplementary material available at https://doi.org/10.1007/s00192-021-04704-2

Funding S.D. has previously had expenses paid by Contura. There are no funding disclosures for this review article.

\section{Compliance with ethical standards}

Conflicts of interest The authors declare that they have no conflicts of interest.

Open Access This article is licensed under a Creative Commons Attribution 4.0 International License, which permits use, sharing, adaptation, distribution and reproduction in any medium or format, as long as you give appropriate credit to the original author(s) and the source, provide a link to the Creative Commons licence, and indicate if changes were made. The images or other third party material in this article are included in the article's Creative Commons licence, unless indicated otherwise in a credit line to the material. If material is not included in the article's Creative Commons licence and your intended use is not permitted by statutory regulation or exceeds the permitted use, you will need to obtain permission directly from the copyright holder. To view a copy of this licence, visit http://creativecommons.org/licenses/by/4.0/.

\section{References}

1. World Health Organisation Virtual press conference on COVID-19. 2020.

2. Joint RCOG/BSGE Statement on gynaecological endoscopy during the COVID-19 pandemic. 2020.

3. Jha S, Pradhan A. BSUG guidance on management of urogynaecological conditions and vaginal pessary use during the Covid 19 pandemic. https://www.rcog.org.uk/globalassets/ documents/guidelines/2020-04-09-bsug-guidance-onmanagement-of-urogynaecological-conditions-and-vaginalpessary-use-during-the-covid-19-pandemic.pdf. 2020.

4. Joint statement on minimally invasive gynecologic surgery during the COVID-19 pandemic - general—news | AUGS. Accessed 4 October 2020. Available from: https://www.augs.org/jointstatement-on-minimally-invasive-gynecologic-surgery-during-thecovid-19-pandemic

5. Ribal MJ, Cornford P, Briganti A, Knoll T, Gravas S, Babjuk M, et al. European Association of Urology Guidelines Office Rapid Reaction Group: an organisation-wide collaborative effort to adapt the EAU guidelines recommendations to the COVID-19 era. Eur Urol 2020;78(1):21-8.

6. Garritty C, Gartlehner G, Nussbaumer-Streit B, King VJ, Hamel C, Kamel C, et al. Cochrane Rapid Reviews Methods Group offers evidence-informed guidance to conduct rapid reviews. J Clin Epidemiol. 2020;130:13-22. https://doi.org/10.1016/j.jclinepi. 2020.10.007

7. Tricco AC, Antony J, Zarin W, Strifler L, Ghassemi M, Ivory J, et al. A scoping review of rapid review methods. BMC Med. 2015;13(1):224. https://doi.org/10.1186/s12916-015-0465-6.

8. Uwins C, Bhandoria GP, Shylasree TS, Butler-Manuel S, Ellis P, Chatterjee J, et al. COVID-19 and gynecological cancer: a review of the published guidelines. Int J Gynecol Cancer. 2020;30(9): 1424-33.

9. Hasanzadeh M, Azad A, Farazestanian M, Mousavi SL. Covid-19: what is the best approach in gynecological oncology patient management during the coronavirus pandemic? Asia Pac J Clin Oncol. 2020. https://doi.org/10.1111/ajco.13476.

10. De Leeuw RA, Burger NB, Ceccaroni M, Zhang J, Tuynman J, Mabrouk M, et al. COVID-19 and laparoscopic surgery: scoping review of current literature and local expertise. JMIR Public Health Surveill. 2020;6(2):e18928. https://doi.org/10.2196/18928 
11. Wohlin C. Guidelines for snowballing in systematic literature studies and a replication in software engineering. ACM International Conference Proceeding Series. 2014. https://doi.org/10.1145/ 2601248.2601268

12. Brouwers MC, Kho ME, Browman GP, Burgers JS, Cluzeau F, Feder G, et al. AGREE II: Advancing guideline development, reporting and evaluation in health care. CMAJ. 2010;182(18): E839-42.

13. Baethge C, Goldbeck-Wood S, Mertens S. SANRA — a scale for the quality assessment of narrative review articles. Res Integr Peer Rev. 2019;4(1):5.

14. Ficarra V, Novara G, Abrate A, Bartoletti R, Crestani A, de Nunzio $\mathrm{C}$, et al. Urology practice during the COViD-19 pandemic. Minerva Urol Nefrol. 2020;72(3):369-75.

15. RANZCOG. COVID-19: outpatient services; office consultations and procedures. Available from: https://ranzcog.edu.au/news/ covid-19-outpatient-services;-office-consultation. Accessed 4 October 2020.

16. Michel F, Gaillet S, Cornu JN, Robert G, Game X, Phé V, et al. French Association of Urology. COVID-19: recommendations for functional urology. Prog Urol. 2020;30(8-9):414-25.

17. Thakar R, Robinson D, Rantell A, Ness W, Seleme M, Berghmans B. Guidance for the management of urogynecological conditions during the coronavirus (COVID-19) pandemic iuga.org/ publications/covid-19-guidance-for-urogynecological-conditions. 2020

18. Society for Gynecologic Surgeons. Joint statement on reintroduction of hospital and office-based procedures in the COVID-19 climate for the practicing urogynecologist and gynecologist. J Minim Invasive Gynecol. 2020;27(5):1030-32.

19. Grimes CL, Balk EM, Crisp CC, Antosh DD, Murphy M, Halder $\mathrm{GE}$, et al. A guide for urogynecologic patient care utilizing telemedicine during the COVID-19 pandemic: review of existing evidence. Int Urogynecol J. 2020;31(6):1063-89.

20. Amparore D, Campi R, Checcucci E, Sessa F, Pecoraro A, Minervini A, et al. Forecasting the future of urology practice: a comprehensive review of the recommendations by international and European associations on priority procedures during the COVID-19 pandemic. Eur Urol Focus. 2020;6(5):1032-48.

21. Chiofalo B, Baiocco E, Mancini E, Vocaturo G, Cutillo G, Vincenzoni C, et al. Practical recommendations for gynecologic surgery during the COVID-19 pandemic. Int J Gynecol Obstet. 2020;150(2):146-50.

22. Grimes CL, Balk EM, Dieter AA, Singh R, Wieslander CK, Jeppson PC, et al. Guidance for gynecologists utilizing telemedicine during COVID-19 pandemic based on expert consensus and rapid literature reviews. Int J Gynecol Obstet. 2020;150:288-98.

23. Novara G, Checcucci E, Crestani A, Abrate A, Esperto F, Pavan N, et al. Telehealth in urology: a systematic review of the literature. How much can telemedicine be useful during and after the COVID19 pandemic? Eur Urol. 2020;78(6):786-811.

24. Katz EG, Stensland KD, Mandeville JA, MacLachlan LS, Moinzadeh A, Sorcini A, et al. Triaging office based urology procedures during the COVID-19 pandemic. J Urol. 2020;204(1): 9-10.

25. Escura Sancho S, Ros Cerro C, Anglès-Acedo S, Bataller Sánchez E, Espuña-Pons M. How did COVID-19 pandemic change the way we attend the patients in an urogynaecological unit. Clin Invest Ginecol Obstet. 2020;47(3):111-7.

26. Serna-Gallegos T, Ninivaggio CS. A lasting impression: telemedicine in urogynecology during the coronavirus disease 2019 pandemic. Curr Opin Obstet Gynecol. 2020;32(6):456-60.

27. Heldwein FL, Loeb S, Wroclawski ML, Sridhar AN, Carneiro A, Lima FS, et al. A systematic review on guidelines and recommendations for urology standard of care during the COVID-19 pandemic. Eur Urol Focus. 2020;6(5):1070-85.

28. López-Fando L, Bueno P, Carracedo D, Averbeck M, Castro-Díaz DM, Chartier-Kastler E, et al. Management of female and functional urology patients during the COVID pandemic. Eur Urol Focus. 2020;6(5):1049-57.

29. Ghanbari Z, Mostaan F, Eftekhar T, Deldar M, Changiz N, Adabi K. Resumption of elective surgery following COVID-19 outbreak, guideline for female pelvic medicine and surgery. J Family Reprod Health. 2020. 14(1):1-4

30. Ahmed K, Hayat S, Dasgupta P. Global challenges to urology practice during the COVID-19 pandemic. BJU Int. 2020;125(6):E5-6.

31. Huri E, Hamid R. Technology-based management of neurourology patients in the COVID-19 pandemic: is this the future? A report from the International Continence Society (ICS) institute. Neurourol Urodyn. 2020;39(6):1885-8.

32. Mukherjee S, Raza A. Virtual consent for virtual patients: benefits of implementation in a peri- and post-COVID-19 era. Br J Hosp Med (Lond). 2020;81(7):1-3.

33. Musco S, del Popolo G, Lamartina M, Herms A, Renard J, Manassero A, et al. Neuro-urology during the COVID-19 pandemic: triage and priority of treatments. Neurourol Urodyn. 2020;39(7): 2011-5

34. Chu DK, Akl EA, Duda S, Solo K, Yaacoub S, Schünemann HJ, et al. Physical distancing, face masks, and eye protection to prevent person-to-person transmission of SARS-CoV-2 and COVID-19: a systematic review and meta-analysis. Lancet. 2020;395(10242): 1973-87.

35. Transmission of SARS-CoV-2 and mitigating measures. EMGSAGE. 2020. https://www.gov.uk/government/publications/ transmission-of-sars-cov-2-and-mitigating-measures-update-4june-2020

36. Phé V, Karsenty G, Robert G, Gamé X, Cornu JN. Widespread postponement of functional urology cases during the COVID-19 pandemic: rationale, potential pitfalls, and future consequences. Eur Urol. 2020;78(1):4-5.

37. Galvão J. COVID-19: the deadly threat of misinformation. Lancet Infect Dis. 2020. https://doi.org/10.1016/S1473-3099

Publisher's note Springer Nature remains neutral with regard to jurisdictional claims in published maps and institutional affiliations. 